\title{
CYP20-3 deglutathionylates 2-CysPRX A and suppresses peroxide detoxification during heat stress
}

\author{
Wenshan Liu*, Izailda Barbosa dos Santos*, Anna Moye, Sang-Wook Park (1)
}

\begin{abstract}
In plants, growth-defense trade-offs occur because of limited resources, which demand prioritization towards either of them depending on various external and internal factors. However, very little is known about molecular mechanisms underlying their occurrence. Here, we describe that cyclophilin 20-3 (CYP20-3), a 12-oxo-phytodienoic acid (OPDA)-binding protein, crisscrosses stress responses with lightdependent electron reactions, which fine-tunes activities of key enzymes in plastid sulfur assimilations and photosynthesis. Under stressed states, OPDA, accumulates in the chloroplasts, binds and stimulates CYP20-3 to convey electrons towards serine acetyltransferase 1 (SAT1) and 2-Cys peroxiredoxin A (2CPA). The latter is a thiol-based peroxidase, protecting and optimizing photosynthesis by reducing its toxic byproducts (e.g., $\mathrm{H}_{2} \mathrm{O}_{2}$ ). Reduction of 2CPA then inactivates its peroxidase activity, suppressing the peroxide detoxification machinery, whereas the activation of SAT1 promotes thiol synthesis and builds up reduction capacity, which in turn triggers the retrograde regulation of defense gene expressions against abiotic stress. Thus, we conclude that CYP20-3 is a unique metabolic hub conveying resource allocations between plant growth and defense responses (trade-offs), ultimately balancing optimal growth phonotype.
\end{abstract}

DOI 10.26508/Isa.202000775 | Received 12 May 2020 | Revised 17 July 2020 | Accepted 21 July 2020 | Published online 30 July 2020

\section{Introduction}

Peroxiredoxins (PRXs) are ubiquitous and the most abundant thiolbased peroxidases capable of reducing a broad range of toxic peroxides in the presence of sufficient electron $\left(\mathrm{H}^{+}, \mathrm{e}^{-}\right)$donors. The peroxidase cycle starts by their redox-active cysteine (Cys; the peroxidatic $C_{S}, C_{P}$ ) in the catalytic center that is oxidized to sulfenic acid $\left(\mathrm{C}_{P}-\mathrm{SOH}\right)$ by a broad set of peroxide substrates. The $\mathrm{C}_{\mathrm{P}}-\mathrm{SOH}$ residue then reacts either with another Cys of the same or an adjacent subunit, or with another thiol-containing compound, to form an inter- or intramolecular disulfide $\left(C_{P}-S-S-C_{R}\right)$, which is later reduced (via a mixed disulfide with a reductant) to reform the thiolate (Perkins et al, 2015; Liebthal et al, 2019).

In Arabidopsis, the nuclear genome encodes two plastid 2CysPRX (2CP) isoforms (denoted A and B) that play crucial, versatile roles in plant growth and survival, acting as reductase, redox sensor, and chaperone, along with their peroxidase detoxification property in protecting and modulating photosynthetic mechanisms (Muthuramalingam et al, 2009). However, 2CPs are known to typically form an obligatory homodimer as the $C_{P}$ from one monomer is connected via a disulfide bond to the resolving Cys $\left(C_{R}\right)$ located at another monomer. The oxidation of $C_{P}$ then, in consequence, deactivates the catalytic activity of $2 \mathrm{CPS}$. Thus, $2 \mathrm{CP}$ dimers require electron donors such as an NADPH-dependent thioredoxin reductase C (NTRC), thioredoxins (TRXs), and/or cyclophilin 20-3 (CYP20-3), which reduces (activates) them to be able to metabolize the detoxification of a toxic by-product in photosynthesis (i.e., $\mathrm{H}_{2} \mathrm{O}_{2}$ ), and the activation of Calvin cycle enzymes such as fructose 1,6-bisphosphatase (Dietz et al, 2006; Caporaletti et al, 2007; Laxa et al, 2007; Muthuramalingam et al, 2009; Liebthal et al, 2016). Therefore, deficiency of 2CPs in antisense, and T-DNA insertion mutant plants manifested the increased levels of $\mathrm{H}_{2} \mathrm{O}_{2}$ and carbonylated proteins, while decreasing the quantum yield of PSII and $\mathrm{CO}_{2}$ fixation rates, which together result in growth and developmental inhibition (Baier \& Dietz, 1999; Baier et al, 2000; Pulido et al, 2010; Awad et al, 2015).

On the other hand, 2CPs could display an array of oligomeric structures upon cellular positions and conditions, as well as other posttranslational modifications (PTMs; Perkins et al, 2015; Liebthal et al, 2019). Under oxidative stress, 2CPs could be overoxidized and form a homodecameric complex that disables their peroxidase activity, but instead gains a chaperon activity to protect cellular molecules against oxidative damage (Liebthal et al, 2019). However, recent studies with human Prxl (huPrxl) and pea 2CP have argued that 2CPs are rather S-glutathionylated by GSSG during oxidative stress, protecting their quaternary structures to remain as dimers and, as a result, enzymatically inactivated status (Park et al, 2009, 2011; Calderón et al, 2017).

Among several plastid enzymes of which transcripts are coregulated with 2CPs, stromal CYP20-3 is one that appeared to directly interact with them (Muthuramalingam et al, 2009; Cheong et al, 2017). CYP20-3 is a dual enzyme, exerting chaperon (i.e., peptidylprolyl cis-trans isomerase and PPlase) and reductase activities (Laxa et al, 2007; Park et al, 2013), positioned as a regulatory hub between the light-dependent reaction in photosynthesis and 12oxo-phytodienoic acid (OPDA) signaling (Cheong et al, 2017). OPDA is

Department of Entomology and Plant Pathology, Auburn University, Auburn, AL, USA

Correspondence: swpark@auburn.edu

*Wenshan Liu and Izailda Barbosa dos Santos contributed equally to this work 
a primary precursor of (-)-jasmonic acid (JA), able to trigger an autonomous signaling pathway that regulates unique subsets of jasmonate-responsive genes, activating and fine-tuning plant defense responses, as well as growth processes (Böttcher \& Pollmann, 2009; Dave \& Graham, 2012). Its distinctive activity was first described by the pathoanalyses of a mutant Arabidopsis (opr3) arresting the conversion of OPDA to JA (Stintzi et al, 2001). Wild type (WT)-like resistance of opr3, in contrast to decreased resistance in mutant plants disrupting trienoic fatty acid biosynthesis ( $\mathrm{fad} 3 / 7 / 8$ ) and the octadecanoid pathway (dde2 and aos), against fungal and insect infections underlined the essential roles of OPDA signaling in plant defense responses in the absence of JA and JA-Ile (Stintzi et al, 2001; Zhang \& Turner, 2008; Stotz et al, 2011). Following studies with several mutant plants, suppressing or impairing JA production (e.g., siOPR3, OPR3-RNAi, cts-2/opr3 and acx1) or OPDA signaling (cyp-203) further substantiated that OPDA signaling is crucial in basal defense responses against a variety of pathogenic fungi and insects, such as Alternaria brassicicola, Botrytis cinerea, Scierotinia sclerotiarum, Nilaparvata lugens, Manduca sexta, and Bradysia impatiens, as well as seed germination, embryogenesis, and balancing abscisic acid signaling (Dave et al, 2011; Goetz et al, 2012; Park et al, 2013; Bosch et al, 2014; Guo et al, 2014; Scalschi et al, 2015).

Under stressed conditions, OPDA, accumulates in the chloroplasts, binds and promotes CYP20-3 to transfer electrons from the photosystem I (PSI) via TRXs (type-f2 and $-\mathrm{x}$ ) towards 2CPs (Motohashi et al, 2001; Laxa et al, 2007; Dominguez-Soils et al, 2008; Cheong et al, 2017) or a serine acetyltransferase 1 (SAT1, Dominguez-Soils et al, 2008; Park et al, 2013). Reduction of 2CPs then controls peroxide (photo-oxidant) detoxifications and photosynthetic carbon metabolisms (Dietz et al, 2006; Caporaletti et al, 2007), whereas the activation of SAT1 stimulates the plastid sulfur assimilation, which leads to the production of Cys and thiol metabolites (e.g., glutathione; GSH), and the buildup of cellular reduction potential (Park et al, 2013). The enhanced reduction capacity, in turn, coordinates the expression of a subset of OPDA-responsive genes (ORGs) and general defense regulators (e.g., glutaredoxin 480) in controlling basal and racespecific (local and systemic) resistances and defense responses against various abiotic stresses (Mou et al, 2003; Park et al, 2013).

Collectively, available data suggest that the functional dynamics of 2CP isoforms in conjunction with CYP20-3-dependent OPDA signaling fine-tunes energy inputs into outputs that shape plant growth and defense response ("trade-offs"), programing optimal phenotypes under different ecological conditions. In this context, the present study demonstrates that heat stress (HS) prompts CYP20-3 to temporally limit an antioxidant machinery of GSHglutathionylated $2 \mathrm{CPA}\left(2 \mathrm{CPA}{ }^{\mathrm{GS}}\right)$ in photosynthesis, while relaying an OPDA signal, which triggers the retrograde regulation of nucleus defense gene (e.g., HSP17.6, HSP70, and CYP18D11) expressions. The HS responses explain a unique molecular mechanism underlying the mode of resource allocations between plant growth and defense responses. Besides, these data also highlight a novel activity of GSH as a functional group of posttranslational modifiers, apart from its antioxidant activity, which determine (i) the quaternary structure and (ii) the cellular activity of enzymes (e.g., $2 \mathrm{CP}^{\mathrm{GS}}$ isoforms), and (iii) directed their metabolic pathways (i.e., reductant signaling), controlling the interface between plant growth, defense responses, and stress acclimation processes.

\section{Results}

\section{$2 \mathrm{CPA}^{\mathrm{GS}}$ and $2 \mathrm{CPB}^{\mathrm{GS}}$ form discrete quaternary structures}

Recently, emerging evidence have elucidated a critical role of redoxmediated PTM in resolving the cellular property and modus operandi of 2CPs (Park et al, 2009, 2011; Calderón et al, 2017). In agreement, our preparatory analyses uncovered that 2CPs, prepared recombinantly in Escherichia coli, uniquely bind a negatively charged tripeptide GSH, a major nonprotein thiol antioxidant in plants (Fig S1). GSH-binding (hereafter, called GSH-glutathionylation) then differentially modulates the conformational states of 2CPs (Fig 1A lanes 1,2, 5, and 6, and Fig S2), stimulating predominantly the monomerization and peroxidase activity of 2CPA, while decamerizing and accentuating the chaperone activity of 2CPB (Fig S3, Lee et al, 2015).

However, the two plastid 2CPs, sharing a high sequence identity ( $>96 \%$ in amino acids, Fig S4), have been considered to be functionally and structurally redundant, controlling peroxide detoxifications and carbon metabolisms in photosynthesis (Kirchsteiger et al, 2009; Pulido et al, 2010). Thus, to further scrutinize whether the distinctive conformations are an intrinsic property of $2 \mathrm{CPS}^{\mathrm{GS}}$ and not caused by noncoding amino acids derived from expression vectors, we re-prepared and examined quaternary structures of the "tag-free" version of recombinant 2CPs (called as 2CPs hereafter, Fig 1A). As anticipated, 2CPs and $2 \mathrm{CPS}^{\mathrm{GS}}$ displayed mostly a similar format of quaternary structures to His-tagged $2 \mathrm{CPs}$ and $2 \mathrm{CPs}{ }^{\mathrm{GS}}$. A notable variance was that $2 \mathrm{CPA}^{\mathrm{GS}}$ comprised only di- and monomers (Fig $1 \mathrm{~A}$ lane 4), whereas His-tagged $2 \mathrm{CPA}^{\mathrm{GS}}$ constituted a tripartite conformation, that is, deca-, di-, and monomers (lane 2). Nevertheless, both $2 \mathrm{CPB}^{\mathrm{GS}}$ and His-tagged $2 \mathrm{CPB}^{\mathrm{GS}}$ alike formed icosa- and decameric conformations (lanes 6 and 8), supporting an earlier notion that $2 \mathrm{CPA}^{\mathrm{GS}}$ and $2 \mathrm{CPB}^{\mathrm{GS}}$ configure distinctive quaternary states (Figs $\mathrm{S} 2$ and $3 \mathrm{~A}$ ) and, in consequence, confer unique cellular functions as a peroxidase $\left(2 \mathrm{CPA}{ }^{\mathrm{GS}}\right.$, Fig $\mathrm{S} 3 \mathrm{~B})$ and a molecular chaperone $\left(2 \mathrm{CPB}^{\mathrm{GS}}\right.$, Fig $\left.\mathrm{S} 3 \mathrm{C}\right)$, respectively.

\section{Positions of Val and lle determine discrete quaternary structures between $2 \mathrm{CPA}^{\mathrm{GS}}$ and $2 \mathrm{CPB}^{\mathrm{GS}}$}

Mature 2CP sequences differ in seven amino acids (Fig S4), suggesting that those residues are likely responsible for the disparate formation of quaternary structures between $2 \mathrm{CPA}^{\mathrm{GS}}$ and $2 \mathrm{CPB}^{\mathrm{GS}}$. To substantiate this hypothesis, we comparatively surveyed the quaternary structures of single and double-mutant 2CPBs of which specific amino acids were replaced with corresponding ones in $2 \mathrm{CPA}$ (i.e., $\mathrm{E}_{33} \mathrm{D}, \mathrm{Y}_{64} \mathrm{H} / \mathrm{E}_{65} \mathrm{~S}, \mathrm{~V}_{106} \mathrm{I} /$ $\mathrm{I}_{109} \mathrm{~V}, \mathrm{P}_{122} \mathrm{H}$, and $\mathrm{V}_{157}$; Fig 1B). Most mutant 2CPBs and $2 \mathrm{CPBS}^{\mathrm{GS}}$ however exhibited the WT-like quaternary structure, except one $\left(V_{106} \mathrm{I} / \mathrm{I}_{109} \mathrm{~V}\right)$. The two nearby amino acids, $V_{106}$ and $I_{109}$, in 2CPB were switched to $I_{106}$ and $V_{109}$, respectively, located at the corresponding positions in 2CPA. This mutant $2 \mathrm{CPBV}_{106} \mathrm{l} / \mathrm{I}_{109} \mathrm{~V}$ indeed behaved like 2CPA, unable to form decaand icosamers but releasing monomers upon GSH-glutathionylation (Fig $1 \mathrm{~B}$ lane 4 and 10). In comparison, an analogous mutant $2 \mathrm{CPAl}_{106} \mathrm{~V} / \mathrm{V}_{109} \mathrm{I}$ exhibited 2CPB-like behavior (Fig 1B lane 14), illuminating a crucial role of Val and Ile, and their specified positions at 106 and 109 in the oligomerization of $2 \mathrm{CPB}$, as well as $2 \mathrm{CPB}^{\mathrm{GS}}$. A series of hydrophobic connections via $V_{106}$ from one monomer and $I_{109}$ located at another monomer may lead to the decamerization of $2 \mathrm{CPB}$ and $2 \mathrm{CPB}^{\mathrm{GS}}$. Conversely, the reverse positions of $\mathrm{I}_{106}$ and $\mathrm{V}_{109}$ in 2CPA structurally discommoded the $\mathrm{V}-\mathrm{I}$ 

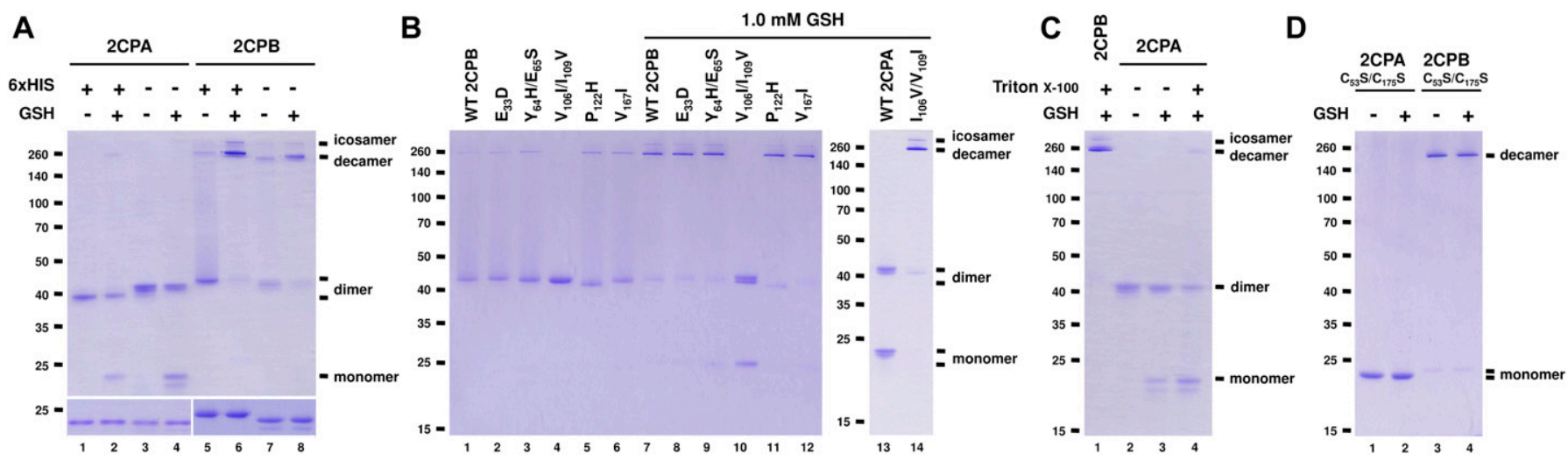

Figure 1. Val and Ile determine different quaternary structures between $2 \mathrm{CPA}^{\mathrm{GS}}$ and $2 \mathrm{CPB}^{\mathrm{GS}}$.

(A, B, C, D) Redox shift visualization of WT and/or mutant $2 \mathrm{CPS}^{\mathrm{GS}}$. (A) His- and nontagged versions of $2 \mathrm{CPA}$ or $2 \mathrm{CPB}(1 \mu \mathrm{M})$ were incubated with/without $1 \mathrm{mM}$ GSH and subjected to nonreducing (upper panel) or reducing (lower panel) SDS/PAGE. (B) Mutant $2 \mathrm{CPBS}\left(\mathrm{E}_{33} \mathrm{D}, \mathrm{Y}_{63} \mathrm{H} / \mathrm{E}_{65} \mathrm{~S}, \mathrm{~V}_{106} \mathrm{I} / \mathrm{I}_{100} \mathrm{~V}, \mathrm{P}_{112} \mathrm{H}\right.$, and $\left.\mathrm{V} 167 \mathrm{I} ; 1 \mu \mathrm{M}\right)$ and mutant $2 \mathrm{CPA}\left(\mathrm{I}_{106} \mathrm{~V} /\right.$ $\mathrm{V}_{109} \mathrm{l} ; 1 \mu \mathrm{M}$ ) were incubated with/without $1 \mathrm{mM}$ GSH. (C) WT 2CPA or 2CPB (1 $\mu \mathrm{M}$ ) was incubated with/without $1 \mathrm{mM}$ GSH and/or 0.1\% (vol/vol) Triton X-100. (D) Cys to Ser mutant $2 \mathrm{CPS}\left(\mathrm{C}_{53} \mathrm{~S} / \mathrm{C}_{175} \mathrm{~S} ; 1 \mu \mathrm{M}\right)$ were incubated with/without $1 \mathrm{mM} \mathrm{GSH}$. Data information: In (A, B, C, D), recombinant 2 CPs were produced in E. coli and purified by a nickel column, as described in the Materials and Methods section. Gels were stained with Coomassie Brilliant Blue, and standard molecular weight sizes were indicated in the left of gels. Each lane number was denoted below the gel. In (B, C, D), all proteins were tag-free versions and separated via nonreducing SDS/PAGE.

Source data are available for this figure.

interactions and a subsequent decamerization of $2 \mathrm{CPA}^{\mathrm{GS}}$ (Fig 1C). A partial denaturation (relaxation) of its tertiary structure enabled to form decameric complexes upon the GSH-glutathionylation (Fig 1C lane 4 versus 2 and 3). In addition, the disruption of intradisulfide bonds in $\mathrm{C}$ to $\mathrm{S}$ mutant $2 \mathrm{CPS}\left(\mathrm{C}_{53} \mathrm{~S} / \mathrm{C}_{175} \mathrm{~S}\right)$ casts an action on the $\mathrm{V}-\mathrm{I}$ interactions which resulted predominantly in decameric $2 \mathrm{CPB}$, in contrast to the monomeric $2 \mathrm{CPA}$ produced, regardless of the GSH-glutathionylation (Fig 1D). It is though notable that mutant $2 \mathrm{CPBC}_{53} \mathrm{~S} / \mathrm{C}_{175} \mathrm{~S}$, unlike $2 \mathrm{CPB}^{\mathrm{GS}}$ (Fig $1 \mathrm{~A}$ lane 7 and 8 ), did not form icosamers (Fig 1D lanes 3 and 4), indicating that the S-S interactions maybe needed for the icosamerization of $2 \mathrm{CPB}$ and $2 \mathrm{CPB}^{\mathrm{GS}}$, perhaps via the dimerization of decameric 2CP complexes.

\section{Increased ratios of GSH:GSSG coordinate the GSH-glutathionylation of 2CPA}

Next, we investigated whether cellular GSH homeostasis may influence the rate of GSH-glutathionylation of 2CPs. For instance, earlier studies from our and other groups revealed that the activation of plant defense responses via salicylic acid (SA) and OPDA signaling systematically induce GSH synthesis, independent of oxidative stress signaling, and build up cellular reduction potentials (increased GSH-to-GSSG ratio, Mou et al, 2003; Park et al, 2013). In a resting state, the chloroplasts that produce SA and OPDA maintained GSH-to-GSSG ratios of 14:1 (Koffler et al, 2013), and these escalated up to $\geq 28: 1$ under stress conditions (Park et al, 2013). The enhanced redox capacity then stimulates the GSH-glutathionylation and monomerization of $2 \mathrm{CPA}^{\mathrm{GS}}$ (Fig $2 \mathrm{~A}$ lane $3-5$ ), which in turn likely accentuated its peroxidase activity (Fig S3B). $2 \mathrm{CPB}^{\mathrm{GS}}$ however was unresponsive to the elevated level of GSH and maintained largely deca- and icosamers (Fig 2B). On the contrary, decreased reduction (GSH-to-GSSG ratio) capacity displayed little effect on the GSH-glutathionylation of both 2CPs (Fig 2A and B lanes 6 and 7). The latter further supports a unique and autonomous activity of GSH in activating redox signaling, independent of GSSG-mediated S-glutathionylation and its oxidative signaling (Xiong et al, 2011; Grek et al, 2013), that relays hormone (e.g.,
OPDA; Fig S5) signaling during the stress-responsive activation of defense and acclimation pathways.

\section{GSH-glutathionylation suppresses the reducing activity of NTRC, TRX, and SRX towards $2 \mathrm{CPs}^{\mathrm{GS}}$}

Previously, several in vitro studies have surveyed the reducing activity of major plastid redox mediators, elucidating that TRX and NTRC can break up symmetrical S-S bridges in 2CP dimers, or that sulfiredoxin (SRX) deglutathionylates a GS-S bond in 2CPS ${ }^{\text {GS }}$ (Park et al, 2009; Yoshida \& Hisabori, 2016). We hence examined whether and how TRX, NTRC, and/or SRX metabolize the structure and function of $2 \mathrm{CP}^{\mathrm{GS}}$. Note however that the reaction of TRX and NTRC often required excessive reducing powers $(\geq 500$ $\mu \mathrm{M}$ DTT or NADPH, Yoshida \& Hisabori, 2016), $\geq 300$-fold greater than the physiological concentration of NADPH ( $<1.5 \mu \mathrm{M}$; Maruta et al, 2016), that in consequence caused the nonenzymatic reduction, perhaps deglutathionylation, of 2CPS GS (Fig S6). Therefore, we lowered the level of supplement of $\mathrm{DTT}(10 \mu \mathrm{M})$ and $\mathrm{NADPH}(50 \mu \mathrm{M})$ to avoid their direct impacts on the redox state of $2 \mathrm{CPS}^{\mathrm{GS}}$ (Fig 3A-D). Herein, TRX and NTRC exhibited minimal reductase activity, exhibiting little if any effect on the quaternary structure of $2 \mathrm{CPS}^{\mathrm{GS}}$. Likewise, SRX did not metabolize nor deglutathionylate $2 \mathrm{CPS}^{\mathrm{GS}}$ (Fig $3 \mathrm{E}$ and F). Though, it was noticeable that the supplement of SRX causes a slight delay in the gel mobility of partial $2 \mathrm{CPBS}^{\mathrm{GS}}$ (Fig 3F), indicating that SRX may be able to target the S-S bond forming $2 \mathrm{CPB}^{\mathrm{GS}}$ icosamers (Fig 1D). Indeed, a daily expression rhythm of $S R X$ was coregulated with those of $2 C P$ transcripts (Fig $3 \mathrm{G}$ and $\mathrm{H}$ ). When plants were grown under 12-h light/12-h dark diurnal conditions, the expression of both 2CPA and 2CPB was hiked along with $S R X$ in the afternoon, supporting a potential activity of SRX towards $2 \mathrm{CPS}^{\mathrm{GS}}$. However, TRX peaked at darkness, whereas NTRC was constitutive, projecting its biochemical and biological irrelevance to $2 \mathrm{CPS}{ }^{\mathrm{GS}}$. Caveat is that 2CPs are highly abundant ( $0.6 \%$ of the total plastid proteins) and determined to exhibit slow turnover rates (Horling et al, 2003; Dietz et al, 2006). Hence, the co-expression of 2CPS and SRX may not, at once, tie in their physiological and functional interactions. 
A

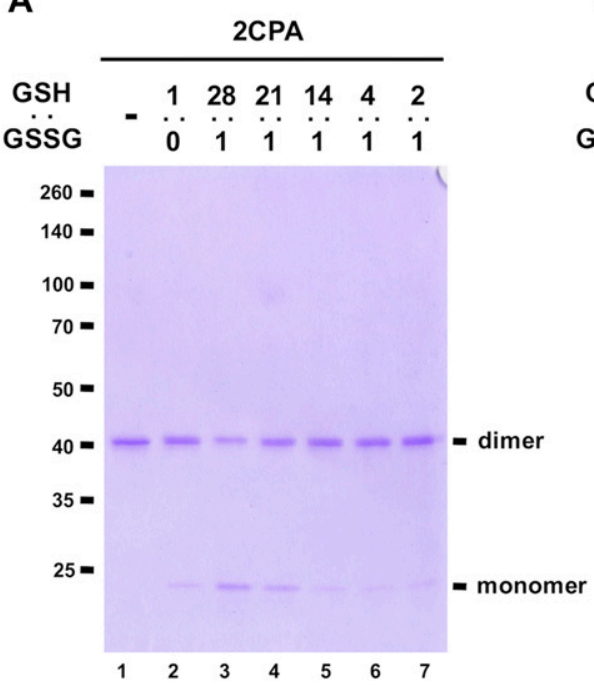

B

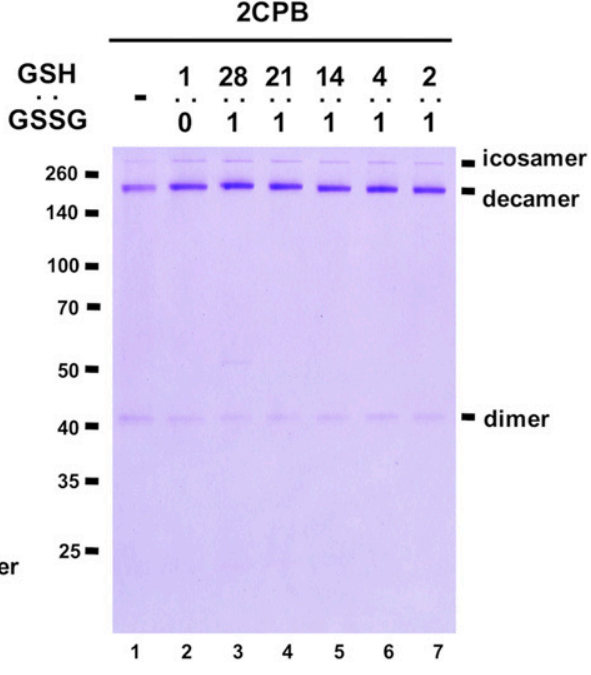

Figure 2. Redox potential controls the conformational and functional state of $2 \mathrm{CPA}^{\mathrm{GS}}$ (A, B) The $1 \mu \mathrm{M}$, tag-free recombinant 2CPA (A) and 2CPB (B), incubated with different ratios of $1 \mathrm{mM} \mathrm{GSH:GSSH}$ (1: $0,28: 1,21: 1,14: 1,4: 1$, and 2:1) were subjected to nonreducing SDS/PAGE and stained with Coomassie Brilliant Blue. Standard molecular weight sizes were indicated in the left of gels.

Source data are available for this figure.

\section{CYP20-3 deglutathionylates $2 \mathrm{CPA}^{\mathrm{GS}}$ at high temperatures}

A series of protein-protein interaction and DNA protection analyses have inferred that CYP20-3 is another electron donor of 2CPs (Laxa et al, 2007; Muthuramalingam et al, 2009; Cheong et al, 2017), but our redox-shifting assays did not detect any reductase activity of CYP20-3 towards $2 \mathrm{CPS}{ }^{\mathrm{GS}}$ (Fig S7). We therefore speculated whether CYP20-3 confers rather PPlase activity and protects $2 \mathrm{CPs}{ }^{\mathrm{GS}}$ from thermal aggregations (at $45^{\circ} \mathrm{C}$, Bhuwan et $\mathrm{al}$, 2017). However, $2 \mathrm{CPs}^{\mathrm{GS}}$ turned out to be heat stable (Fig $4 \mathrm{~A}$ and $\mathrm{B}$ lane 2), making us unable to measure the chaperone activity of CYP20-3. We instead noticed at $\geq 36^{\circ} \mathrm{C}$ that CYP20-3 becomes able to convert monomeric $2 \mathrm{CPAs}{ }^{\mathrm{GS}}$ to dimers (Fig $4 \mathrm{~A}$ lane 5 and 6 ), although it shows little effect on $2 \mathrm{CPB}^{\mathrm{GS}}$ (Fig $4 \mathrm{~B}$ lanes 5 and 6). When incubated at $42^{\circ} \mathrm{C}$, CYP20-3 was able to reduce a mixed GS-S bond (i.e., deglutathionylation, Fig 4 C right panel) and led $2 \mathrm{CPA}^{\mathrm{GS}}$ to form an obligatory dimer (Fig $4 \mathrm{C}$ left panel). On the other hand, CYP20-3 dissipated icosameric 2CPB ${ }^{\mathrm{GS}}$ (Fig 4D right panel) proposing either (i) its target-specific deglutathionylation activity to $2 \mathrm{CPB}^{\mathrm{GS}}$ icosamers or (ii) its ability to break a proposed S-S bonds between decameric $2 \mathrm{CPBS}^{\mathrm{GS}}$ (see above in Fig 1D). Nonetheless, most $2 \mathrm{CPB}^{\mathrm{GS}}$ (or $2 \mathrm{CPB}$ ) remained as decamers, an active molecular chaperone (Fig 4D left panel), disregarding a substantial activity of CYP20-3 towards $2 \mathrm{CPB}^{\mathrm{GS}}$. Moreover, the high temperature $\left(42^{\circ} \mathrm{C}\right)$ caused little change in the catalytic accessibility of $2 \mathrm{CPS}^{\mathrm{GS}}$ to other reductases such as NTRC, TRX, and SRX (Figs S8 and S9). Thus, these observations indicated the specific and decisive roles of CYP20-3 in HS-dependent deglutathionylation of $2 \mathrm{CPA}^{\mathrm{GS}}$.

\section{CYP20-3 blocks the peroxidase activity of $2 \mathrm{CPA}^{\mathrm{GS}}$ during heat-shock stress}

Our data explain that a reduction of $2 \mathrm{CPA}^{\mathrm{GS}}$ frees GSH (deglutathionylation) and makes up 2CPA dimers (Fig 4C). These conversely resemble the $\mathrm{H}_{2} \mathrm{O}_{2}$-mediated oxidation and inactivation of 2CPA (Fig $1 \mathrm{~A}$ lane 1 and Fig S2B). Indeed, the deglutathionylation of 2CPA ${ }^{\mathrm{GS}}$ paralleled an attenuation of its peroxidase activity, reducing $\mathrm{H}_{2} \mathrm{O}_{2}$ (Fig $5 \mathrm{~A}$ ), indicating that CYP20-3 conveys a temporal suppression of the $\mathrm{H}_{2} \mathrm{O}_{2}$ detoxification system of $2 \mathrm{CPA}^{\mathrm{GS}}$ during HS. In line with this scenario, $\mathrm{H}_{2} \mathrm{O}_{2}$ levels increased rapidly following $\mathrm{HS}$ (peaking at $\sim 4 \mathrm{~h}$ post $\mathrm{HS}$; hph) and remained till $12 \mathrm{hph}$ in WT, $2 \mathrm{cpb}$ and ntrc, but gradually reduced in cyp20-3, or continued increasing up to $\sim 8 \mathrm{hph}$ in 2 cpal, 2cpall, and 2cpa/2cpb (Fig 5B). Taken together, our data delineate that $\mathrm{HS}$ triggers the rapid bursts of $\mathrm{H}_{2} \mathrm{O}_{2}$ (oxidative stress) signaling, while fostering CYP20-3 to temporally limit the peroxidase activity of $2 \mathrm{CPA}^{\mathrm{GS}}$ (i.e., detoxification system), which in fact supports a notion that $2 \mathrm{CPA}^{\mathrm{GS}}$ is a nonessential component in the protection mechanism against oxidative stress (Laxa et al, 2007). Note that the expression of CYP20-3 and 2CPA was constitutive regardless of HS (Fig 5C).

The acclimation of HS (i.e., HS responses) is largely characterized by expression of a battery of HS proteins (HSPs), many of which are molecular chaperones involved in correct native folding and/or assembly of other proteins (Finka et al, 2011). This explains the HS-induced accumulation of, already abundant, $2 \mathrm{CPB}^{\mathrm{GS}}$ (Fig 5C) that constitutes a stable, decameric conformation (Fig 1) conferring chaperon activity (Fig S3C). On the other hand, HS responses convey plant defense (OPDA) signaling (Muench et al, 2016) that activates CYP20-3-dependent sulfur assimilation in increasing thiol metabolites, which then builds up cellular reduction potential (Park et al, 2013). The enhanced redox capacity, in turn, coordinates the expression of a subset of ORGs, including HSP17.6, CYP81D11, and HSP70 (Figs 5D and S10). Therefore, OPDA-insensitive mutant (cyp20-3) hindered the expression of HS-responsive genes (i.e., ORGs; HSP17.6, HSP70, and CYP81D11), whereas the disruption of an NTRC system assisted increased accumulations of HSP17.6. These results support the versatile activity of CYP20-3 in OPDA signaling, which conveys the activation of disease resistance against $A$. brassicicola and defense responses to different abiotic stresses such as wounding and HS (Park et al, 2013; Figs 5D and S10).

\section{Discussion}

In this study, we attempted to elucidate the molecular basis of unique functions between $2 \mathrm{CPA}^{\mathrm{GS}}$ and $2 \mathrm{CPB}^{\mathrm{GS}}$ isoforms. Until recently, two 2CPs have been considered to be functionally and 

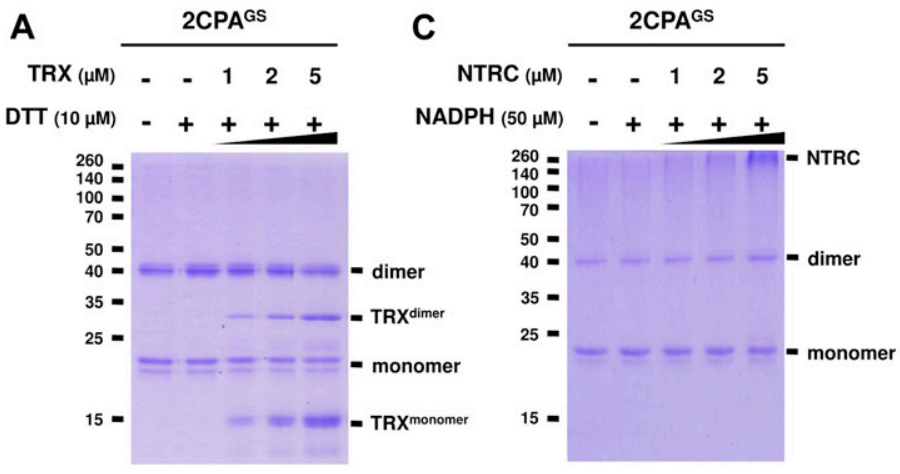

B

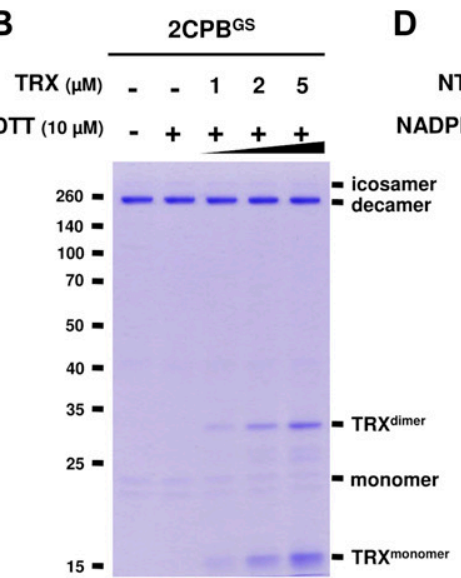

E

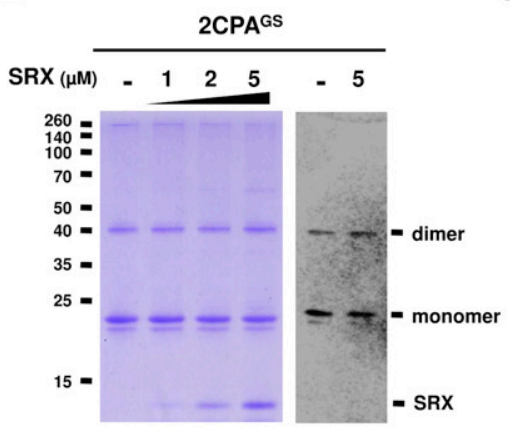

G

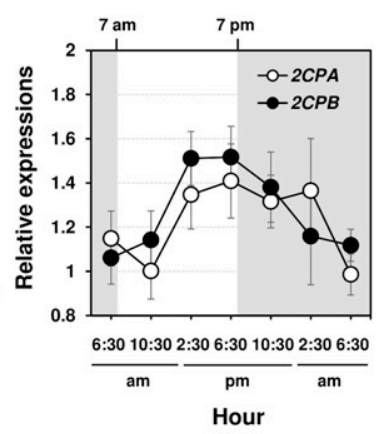

H

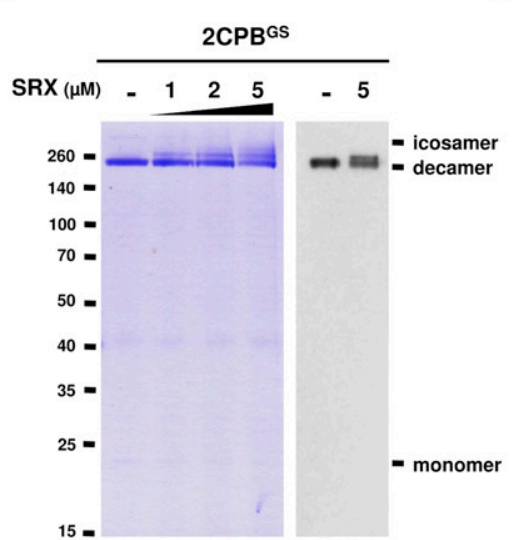

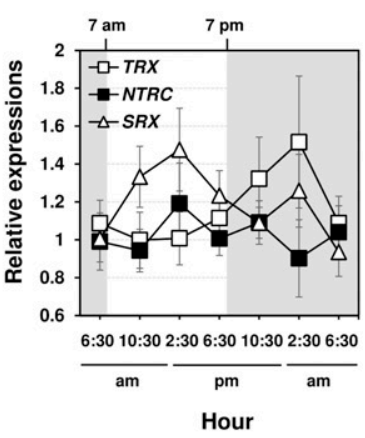

Figure 3. GSH-glutathionylation arrests the catalytic accessibility of $2 \mathrm{CPs}^{\mathrm{GS}}$ towards major plastid-redox mediators, TRX, NTRC, and SRX.

(A, B, C, D, E, F) Redox shift visualization of 2CPS ${ }^{G S} .1 \mu \mathrm{M} 2 \mathrm{CPA}^{\mathrm{GS}}$ and $2 \mathrm{CPB}^{\mathrm{GS}}$ were incubated with DTT/TRX (10 $\mu \mathrm{M}$ DTT and 0-5 $\mu \mathrm{M}$ TRX; A, B), NADPH/NTRC (50 $\mu \mathrm{M}$ NADPH and 0-5 $\mu \mathrm{M} \mathrm{NTRC;}$ C, D), or SRX (0-5 $\mu \mathrm{M}$; E, F). (E, F, right panel) $2 \mathrm{CPA}^{\mathrm{GS}}(\mathrm{E})$ and $2 \mathrm{CPB}^{\mathrm{GS}}(\mathrm{F})$, incubated with/without $5 \mu \mathrm{M}$ SRX were analyzed by Western blot using a monoclonal anti-GSH antibody. All proteins were tag-free, recombinant versions prepared in E. coli BL21 (DE3) and separated by nonreducing SDS/PAGE. Gels were stained with Coomassie Brilliant Blue, and standard molecular weight sizes were indicated in the left of gels. (G, H) Transcript quantification by quantitative RT-PCR of 2CPs (G) and TRX, NTRC, and SRX (H) under diurnal 12-h light/12-h dark conditions. Total RNAs were prepared in every $4 \mathrm{~h}$ from the leaves in WT (Col-0) Arabidopsis plants, and values were normalized to the expression of three reference genes, UBC, GAPDH, and PP2A (means $\pm S D ; n=3$ ).

Source data are available for this figure.

structurally redundant, controlling peroxide detoxifications and carbon metabolisms in photosynthesis (Kirchsteiger et al, 2009; Pulido et al, 2010). A series of biochemical assays however unveiled that 2CPs are an intrinsic target of the GSH-glutathionylation; their protein sulfhydryl groups (PSH) of the resolving $\mathrm{CyS}_{\mathrm{S}}\left(\mathrm{C}_{\mathrm{R}}\right)$ can directly bind and form mixed disulfides with GSH. This PTM then differentially modulates and protects the structure and function of 2CPS against various cellular and ecological constraints, leading to the monomerization and peroxidase activity of $2 \mathrm{CPA}^{\mathrm{GS}}$, while decamerizing and enhancing the chaperone activity of $2 \mathrm{CPB}^{\mathrm{GS}}$.

The key determinant underlying the distinctive quaternary structures between $2 \mathrm{CPS}^{\mathrm{GS}}$ turned out to be two amino acid residues, Val and Ile. Both 2CPs, in fact, contain Val and Ile, but their positions are reversed each other locating at $I_{106}$ and $V_{109}$ in 2CPA, whereas at $\mathrm{V}_{106}$ and $\mathrm{I}_{109}$ in $2 \mathrm{CPB}$. The latter then fit the tertiary structure of $2 \mathrm{CP}$ to allow the $\mathrm{V}-\mathrm{I}$ interactions and make up the decameric complex of $2 \mathrm{CPB}$ and $2 \mathrm{CPB}^{\mathrm{GS}}$. Val and Ile, aliphatic residues are able to form a network of hydrophobic and van der Waals interactions, which often calibrate and stabilize the binding structure of single protein, multiprotein, and protein-ligand systems (Dill \& MacCallum, 2012; Zhu et al, 2016). Indeed, their iso-butyl, sec-butyl, and iso-propyl analogs provide an enhanced capacity for stabilizing the van der Waals interactions (Kathurai et al, 2016), which in turn assists the preferential folding of proteins and protein clusters (Rose \& Wolfenden, 1993). This folding stability perhaps explains greater structural and functional integrity of $2 \mathrm{CPB}^{\mathrm{GS}}$ decamers towards enzymatic and chemical restrictions, than those of monomeric and dimeric $2 \mathrm{CPA}^{\mathrm{GS}}$, and proposes an alternative role in supplying compensatory energy to stress-susceptible interactions and/or the structure versatility within protein complexes.

Besides the V-I interactions, 2CPA's quaternary structures and functions are governed by intra-disulfides and/or the GSH-glutathionylation. Until recently, 2CPA was known to form an obligatory homodimer. The oxidation though deactivates the peroxidase activity of 2CPA and thus requires electron donors such as NTRC, TRXs, and/or CYP20-3, which reduce (activate) dimers to be able to metabolize the removal of toxic peroxides (Laxa et al, 2007; Kirchsteiger et al, 2009; Yoshida \& Hisabori, 2016). However, our studies showed that 2CPA is principally activated through binding to GSH upon arrival at the chloroplasts. GSH herein should be targeting the resolving Cys $\left(C_{R}^{53}\right)$ and enabling $2 \mathrm{CPA}^{\mathrm{GS}}$ to use the peroxidatic Cys $\left(\mathrm{C}_{\mathrm{P}}^{175}\right)$ for catalytic reactions. Hence, monomeric $2 \mathrm{CPAS}^{\mathrm{GS}}$ likely improve the unit of catalytic efficiency, 
A

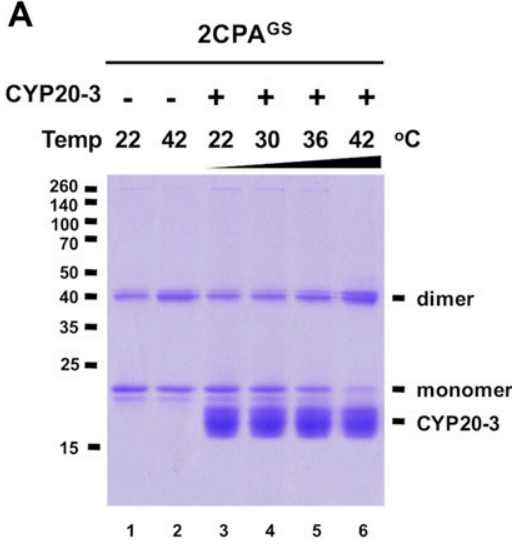

B

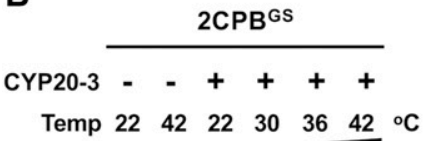

Temp $\begin{array}{lllllll}22 & 42 & 22 & 30 & 36 & 42 & \circ\end{array}$

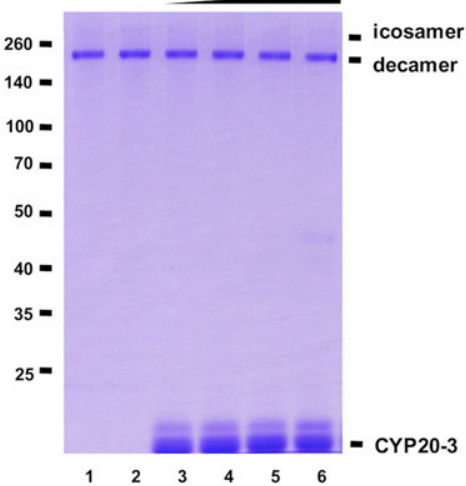

C

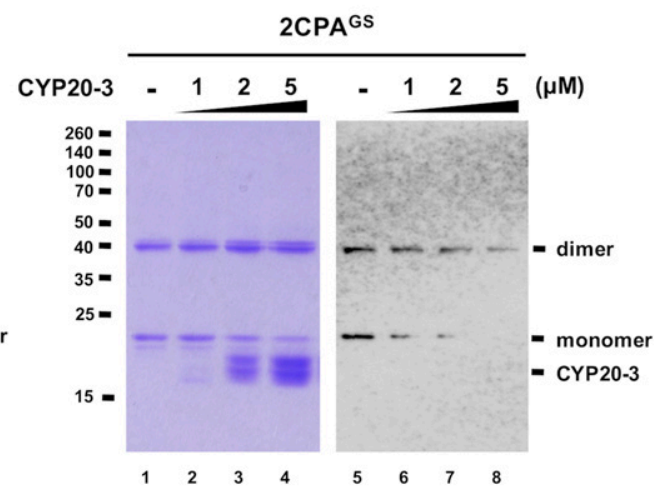

D

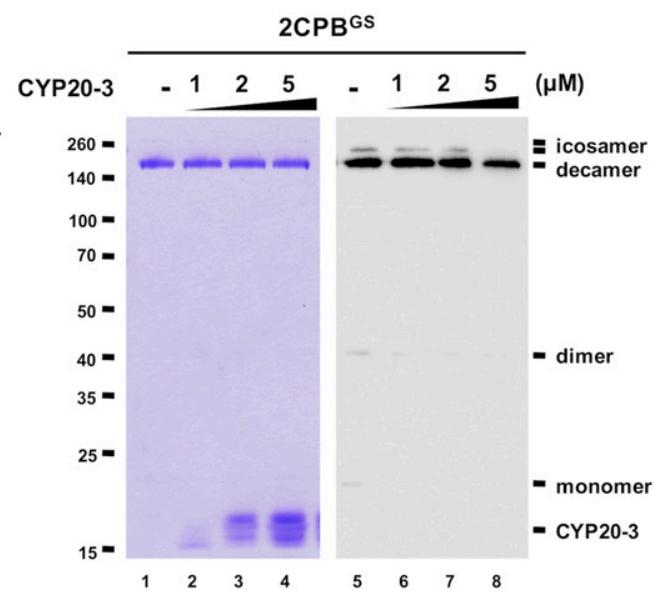

Figure 4. CYP20-3 deglutathionylates $2 \mathrm{CPA}^{\mathrm{GS}}$ at high temperatures.

(A, B) Redox shift visualization of $1.5 \mu \mathrm{M} 2 \mathrm{CPA}^{\mathrm{GS}}$ (A) and $2 \mathrm{CPB}^{\mathrm{GS}}$ (B) incubated with $5 \mu \mathrm{M}$ CYP20-3 under increasing temperatures $\left(22,30,36\right.$, and $\left.42^{\circ} \mathrm{C}\right)$ for 10 min were subjected to nonreducing SDS/PAGE. (C, D) Redox shift visualization of $1.5 \mu \mathrm{M} 2 \mathrm{CPA}^{\mathrm{GS}}$ (C) and $2 \mathrm{CPB}^{\mathrm{GS}}$

(D) incubated with various concentrations of CYP20-3 $(0-5 \mu \mathrm{M})$ at $42^{\circ} \mathrm{C}$ for 15 min were separated in nonreducing SDS/PAGE (left panel) and probed by Western blot analyses using a monoclonal anti-GSH antibody (right panel). Data information: In (A, B, C, D), all proteins were tag-free, recombinant versions prepared in E. coli BL21 (DE3). Gels were stained with Coomassie Brilliant Blue, and standard molecular weight sizes were indicated in the left of gels. Source data are available for this figure. which is fostered nonenzymatically by the enhanced binding kinetics of GSH via increased cellular reduction capacity (increased GSH-toGSSG ratios). On the contrary, an enzymatic reduction proceeds the deglutathionylation (inactivation) of $2 \mathrm{CPA}^{\mathrm{GS}}$. The present study demonstrated that temporal HS can foster the enzymatic accessibility of $2 \mathrm{CPA}^{\mathrm{GS}}$ towards CYP20-3, resulting in a cleavage of a GS-S bond in $2 \mathrm{CPS}^{\mathrm{GS}}$ and a dimerization of 2CPA. The deglutathionylation then inactivates the peroxidase activity of $2 \mathrm{CPs}{ }^{\mathrm{GS}}$, leading to attenuate detoxification mechanisms during HS acclimation processes.

In line with this scenario, earlier studies from our and other groups revealed that the activation of plant defense responses via SA and OPDA signaling systematically induces GSH synthesis independent of oxidative stress signaling (Mou et al, 2003; Park et al, 2013). For instance, OPDA binds and stimulates CYP20-3 to form a complex with SAT1, which triggers the formation of a hetero-oligomeric Cys synthase complex (CSC) with $\mathrm{O}$-acetylserine(thiol)lyase $\mathrm{B}$ in the chloroplasts. CSC formation then leads to the production of Cys (sulfur assimilation) and subsequently GSH, building up reduction capacity, which in turn activates a subset of ORGs (Park et al, 2013), possibly via fostering a target-specific GSH-glutathionylation that modulates the cellular activity of oxidoreductase cascades (Tada et al, 2008) in controlling retrograde signaling, rapidly adjusting nuclear gene expressions to handle diverse ecological conditions (Mou et al, 2003; Park et al, 2013). Note that our jasmonate quantifications in cyp20-3 KO mutants (Park et al, 2013) suggest that in a resting states, CYP20-3 could sequester OPDA and reduce downstream jasmonate productions, but the increased accumulations of OPDA under stress conditions could circumvent the impact of its binding to CYP20-3, exhibiting little difference in JA accumulations between WT and cyp20-3, together proposing that OPDA and JA signaling are activated in parallel and/or accumulatively in defense responses.

Recently, emerging evidence has illuminated a unique activity of plant hormone signaling in converting light inputs into outputs that shape the optimal phenotype ("fitness") towards constant environmental challenges (Ballaré, 2014). The cost of resistance, often referred to as a growth versus defense trade-off, has been typically described as a teeter-totter model where for defense to increase, growth must decrease and vice versa. However, very little is known about the molecular mechanisms underlying their occurrence (Huot et al, 2014). The present study locates CYP20-3 as a unique player in controlling the interface between OPDA signaling (defense) and light-dependent redox reactions (growth). When the PSI antenna captures solar energy (in resting states), it prompts a chain reaction of electron transfers that elicits TRX- and NTRC-based redox regulation in controlling energy (sugar) conversion and consumptions, wherein CYP20-3 is positioned to convey electrons from TRXs towards preferentially SAT1. This maintains a basal-level cellular redox homeostasis (Wirtz \& Hell, 2006; Dominguez-Soils et al, 2008; Takahashi et al, 2011). By contrast, under stressed conditions, OPDA is accumulated and binds CYP20-3 to stimulate its interactions and 
A

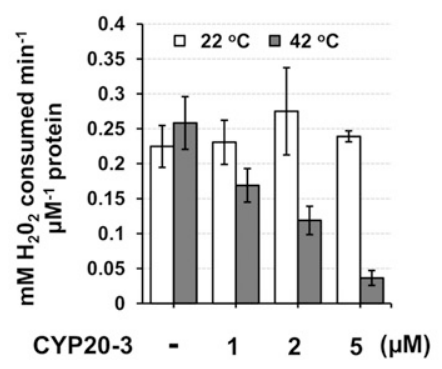

C

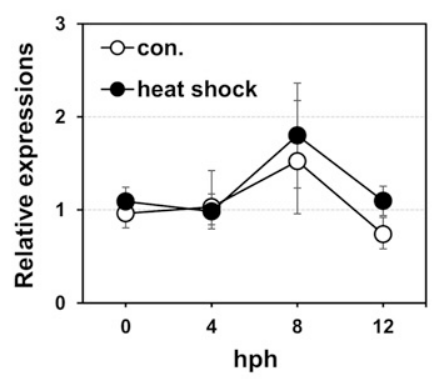

$2 C P B$

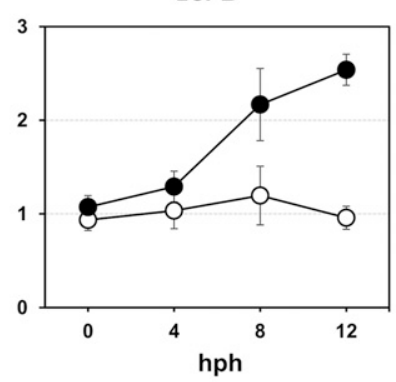

CYP20-3

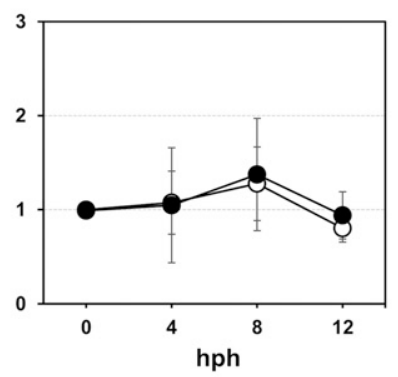

B

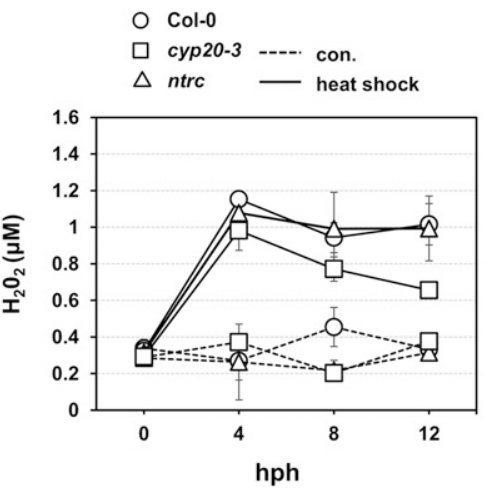

$\Delta 2 c p a l$

- 2cpall

- $2 c p b$

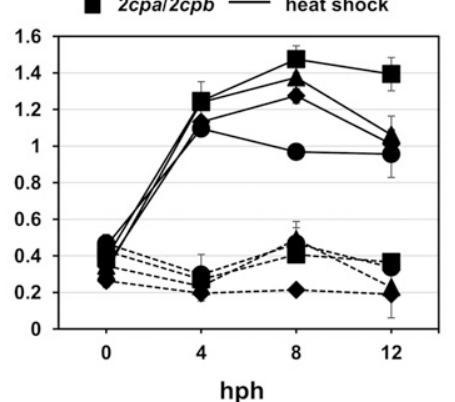

D

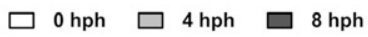

HSP17.6

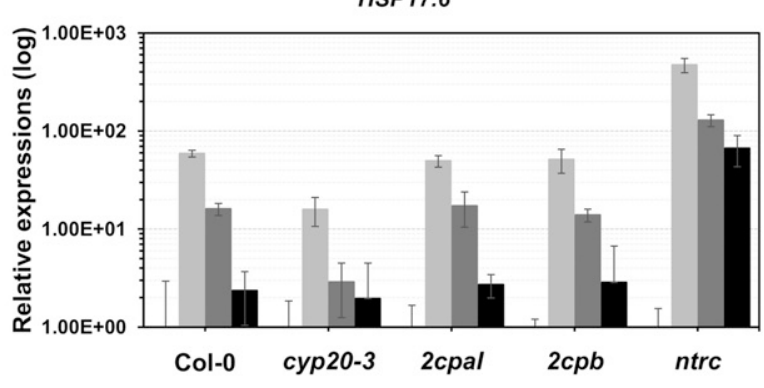

Figure 5. CYP20-3 suppresses a $\mathrm{H}_{2} \mathrm{O}_{2}$-detoxification system of $2 \mathrm{CPA}^{\mathrm{GS}}$ during heat-shock stress.

(A) Peroxidase activity of $2 \mathrm{CPA}^{\mathrm{GS}}$, upon incubation with various concentrations ( $0-5 \mu \mathrm{M}$ ) of $\mathrm{CYP} 20-3$ at $22^{\circ} \mathrm{C}$ (white bars) or $42^{\circ} \mathrm{C}$ (grey bars) for 15 min, was measured by subsequently incubating with $\mathrm{H}_{2} \mathrm{O}_{2}$ for 10 min. $\mathrm{H}_{2} \mathrm{O}_{2}$ was then quantified using the eFOX method (Cheeseman, 2006). 2CPA and CYP20-3 were tag-free, recombinant versions produced in E. coli BL21 (DE3). (B, C, D) Time-resolved (0, 4, 8, 12 hph) measurements of $\mathrm{H}_{2} \mathrm{O}_{2}$ (B), as well as RT-PCR quantifications of 2CPS, CYP20-3 (C), and heat shock protein 17.6 (HSP17.6; D) in heat-stressed WT (Col-0) and/or mutant (cyp20-3, 2cpal, 2cpall, 2cpb, 2cpa/2cpb, and ntrc) plants (means \pm SD; $n=3$ ). Data information: In (C, D), values were normalized to the expression of three reference genes, UBC, GAPDH, and PP2A (means \pm SD; $n=3$ ).

Source data are available for this figure.

electron transfers from TRX-f2 to both SAT1 and 2CPA ${ }^{\mathrm{GS}}$ (Cheong et al, 2017). Reduction (deglutathionylation) of $2 \mathrm{CPA}^{\mathrm{GS}}$ then inactivates photooxidant detoxification and energy biogenesis (Figs 4 and 5), whereas the activation of SAT1 stimulates CSC formation and builds up reduction capacity, which in turn triggers the retrograde regulation of defense gene expression (Park et al, 2013; Cheong et al, 2017). This model sheds new light on (i) a unique interface (CYP20-3) between light and hormone (OPDA) signaling, which (ii) fine-tunes resource (electron) allocations between growth and defense responses (iii) in making instant and appropriate adaptive decisions while being challenged constantly by environmental pressures, maintaining necessary growth and development, and ultimately balancing optimal growth phenotypes (Cheong et al, 2017). The finer aspects of the interactome circuitry of CYP20-3 with reductants (TRXS, 2CPS, and SAT1) will further delineate the regulatory dynamics of balancing acts in optimizing plant fitness, under various forms of environmental pressures.

\section{Materials and Methods}

\section{Preparation of recombinant proteins}

Coding sequences for the mature protein region of 2CPA (At3g11630), 2CPB (At5g06290), NTRC (At2g41680), and SRX (At1g31170) were cloned into the pET28a vector (Novagen) using BamHI/ HindIII (tagged version) and/or Ndel/HindIII (tag-free version). Point mutations of 2CPB were introduced using the QuikChange II site-directed mutagenesis kit (Agilent) according to the manufacturer's instructions. The proteins were then expressed in E. coli BL21 (DE3) and purified by a nickelcolumn (Ni-NTA; QIAGEN) as previously described (Cheong et al, 2017). To remove the His-tag, purified 2CPs and mutant 2CPs were incubated with thrombin protease. The resulting proteins contain additional four nonnative residues (Gly, Ser, His, and Met) at the $\mathrm{N}$ terminus of the protein. Primers used for plasmid constructions and site mutagenesis are listed in Table S1.

\section{S-glutathionylation of 2CPs}

Typically, S-glutathionylation reactions were conducted by incubating 1 or $2 \mu \mathrm{M} 2$ 2Ps with $1.0 \mathrm{mM}$ GSH, GSSG, or GSNO in $50 \mathrm{mM}$ Tris-HCl buffer (pH 7.5) at $25^{\circ} \mathrm{C}$ for $30 \mathrm{~min}$, although some reactions varied GSH concentrations (0.5-10 mM), incubation times (0.5-30 min), or buffer $\mathrm{pH}(7.0-8.0)$.

\section{Preparation of GSH-glutathionylated and oxidized 2CPs}

In 50 mM Tris- $\mathrm{HCl}$ (pH 7.5) buffer, $10 \mu \mathrm{M}$ 2CPs was S-glutathionylated for $30 \mathrm{~min}$ by $10 \mathrm{mM} \mathrm{GSH}$, or oxidized for $15 \mathrm{~min}$ by $0.1 \mathrm{mM} \mathrm{H}_{2} \mathrm{O}_{2}$. Following the reactions, excess $\mathrm{GSH}$ and $\mathrm{H}_{2} \mathrm{O}_{2}$ were removed using size-exclusion chromatography (Sephadex G-25 medium; GE Healthcare) and stored at $4^{\circ} \mathrm{C}$ until use. 


\section{Peroxidase activity assay}

Reduction of $\mathrm{H}_{2} \mathrm{O}_{2}$ by proteins was quantified via the eFOX assay method (Cheeseman, 2006). Briefly, the assay was performed at $37^{\circ} \mathrm{C}$ in $50 \mathrm{mM}$ Tris buffer ( $\mathrm{pH} 7.5$ ) containing $50 \mathrm{mM} \mathrm{NaCl}$ with $5 \mu \mathrm{M}$ $2 \mathrm{CPs}$. Each reaction was initiated by the addition of $50 \mu \mathrm{M} \mathrm{H}_{2} \mathrm{O}_{2}$, then incubated for $10 \mathrm{~min}$, and terminated by $2 \%$ (vol/vol) trichloroacetic acid. A volume of $500 \mu \mathrm{l}$ eFOX reagent $\left(250 \mu \mathrm{M} \mathrm{Fe}\left(\mathrm{NH}_{4}\right)_{2}\left(\mathrm{SO}_{4}\right)_{2}, 100\right.$ $\mu \mathrm{M}$ sorbitol, $100 \mu \mathrm{M}$ xylenol orange, and $1 \%$ [vol/vol] in $20 \mathrm{mM}$ $\mathrm{H}_{2} \mathrm{SO}_{4}$ ) was then mixed with $100 \mu$ lof the reaction solution, and the reduction in $\mathrm{H}_{2} \mathrm{O}_{2}$ levels was tracked spectrophotometrically by measuring the difference in absorbance between 550 and $800 \mathrm{~nm}$.

\section{Chaperone activity assay}

The chaperone activity of 2CPs was measured using citrate synthase as a substrate (Bhuwan et al, 2017). Briefly, $10 \mu \mathrm{M} 2$ CPs was incubated at $45^{\circ} \mathrm{C}$ in $50 \mathrm{mM}$ potassium phosphate buffer ( $\mathrm{pH}$ 7.2). After temperature stabilization for $15 \mathrm{~min}$, citrate synthase ( $1 \mu \mathrm{M}$; SigmaAldrich) was added, and the increase in absorption at $360 \mathrm{~nm}$ was monitored with a spectrophotometer.

\section{Plant materials}

Arabidopsis thaliana WT plants (Col-0) and homozygous T-DNA insertion mutants in 2CPA (SALK_065264; Kangasjärvi et al, 2008 [2cpal]; Ishiga et al, 2012 [2cpall]), 2CPB (SALK_017213; Ishiga et al, 2012), 2CPA/2CPB (Pulido et al, 2010), NTRC (SALK_012208; Stenbaek et al, 2008), CYP20-3 (SALK_120440; Dominguez-Soils et al, 2008), and phytoalexin deficient 2 (pad2; Glazebrook \& Ausubel, 1994) were used in this study. Plants were grown in a chamber with a 12-h day cycle (80-100 $\left.\mu \mathrm{E} / \mathrm{m}^{2} / \mathrm{s}\right)$ at $22^{\circ} \mathrm{C}$ and $60-80 \%$ relative humidity. For HS experiments, $2 \mathrm{~h}$ after dawn, plants were transferred to a growth chamber with these same light conditions but with the temperature set at $42^{\circ} \mathrm{C}$.

\section{Total protein extraction}

Leaf tissues of Arabidopsis were immersed in liquid $\mathrm{N}_{2}$ and ground to a powder using a mortar and pestle. Ground tissue was dissolved into two volumes of $50 \mathrm{mM}$ potassium phosphate buffer $(\mathrm{pH} 7.2)$ containing protease inhibitor cocktails (Sigma-Aldrich), agitated for $60 \mathrm{~min}$, and centrifuged for $30 \mathrm{~min}$ at 10,000 g. The supernatant was collected and immediately used for Western blot analyses. Note that all extraction steps were carried out at $4^{\circ} \mathrm{C}$.

\section{In vitro and ex vivo Western blot analysis}

To assess the quaternary structure of 2CPs, total protein extracts freshly prepared or recombinant $2 \mathrm{CPS}^{\mathrm{GS}}$ were resolved by SDS/ PAGE and electroblotted onto polyvinylidene fluoride membranes (Millipore). The resulting blots were probed with protein G-purified polyclonal rabbit anti-2CPA antibody (1:7,500; MyBioSource) for $2 \mathrm{~h}$, or monoclonal mouse anti-GSH antibody (1:3,000; Enzo Life Science) for $16 \mathrm{~h}$ (for in situ WB) or $2 \mathrm{~h}$ (for in vitro WB), and visualized by chemiluminescence (ECL kit; GE Healthcare). If needed, Ponceau-S red staining was used to verify equal loading.

\section{In situ $\mathrm{H}_{2} \mathrm{O}_{2}$ measurement}

Measurements of endogenous concentrations of $\mathrm{H}_{2} \mathrm{O}_{2}$ and peroxidase activities in Arabidopsis leaf tissues were measured by using the Red Hydrogen Peroxide Assay Kit (Enzo Life Science) according to the manufacturer's instructions. The harvested samples $(100 \mathrm{mg})$ were ground in liquid $\mathrm{N}_{2}$ and suspended in $200 \mu \mathrm{l}$ of $20 \mathrm{mM}$ sodium phosphate buffer ( $\mathrm{pH}$ 7.4). The mixture was centrifuged at 9,500 $\mathrm{g}$ for 10 min at $4^{\circ} \mathrm{C}$, and the supernatant was used for the subsequent assays.

\section{Quantitative RT-PCR}

Total leaf RNA was prepared using TRIzol reagent (Invitrogen) and RNasefree DNase (RQ1; Promega) according to the manufacturer's instructions. RNA qualities were assessed by agarose gel electrophoresis and NanoDrop $\left(A_{260} / A_{280}>1.8\right.$ and $A_{260} / A_{230}>2.0$; Udvardi et al, 2008). cDNA synthesis was performed by using an oligo(dT) reverse primer and a reverse transcriptase (qScript; QuantaBio). Quantitative PCR was performed with the PerfeCT SYBR Green FastMix Reaction Mixes (QuantaBio) in the CFX96 Touch (Bio-Rad) PCR system cycled 40 times by using genespecific primer sets (Table S1). The annealing temperatures for the primer pairs were $53^{\circ} \mathrm{C}$. Data were quality-controlled; normalized against three reference genes, polyubiqutin (UBC), GAPDH, and protein phosphatase $2 \mathrm{~A}$ (PP2A) (Czechowski et al, 2005; Sanchez-Villarreal et al, 2013); and statistically evaluated using qbasePLUS 3.0 (Ramakers et al, 2003). Primers used for qRT-PCR are listed in Table S1.

\section{Supplementary Information}

Supplementary Information is available at https://doi.org/10.26508/lsa. 202000775.

\section{Acknowledgements}

We thank KJ Dietz for sharing pCRT7/NT-TOPO encoding 2CPA (At3g11630) and FJ Cejudo and $\mathrm{K}$ Mysore for providing transfer-DNA insertion lines: 2cpal, $2 c p a l l, 2 c p b, 2 c p a / 2 c p b$, and ntrc. This work was supported by the Alabama Agricultural Experiment Station (Auburn University), the Hatch Program of the National Institute of Food and Agriculture (United States Department of Agriculture), the office of the Vice President for Research and Economic Development (Auburn University), the Alabama Cotton Commission, and the Alabama Farmers Federation.

\section{Author Contributions}

W Liu: conceptualization, data curation, formal analysis, validation, investigation, visualization, and writing-original draft.

I Barbosa Dos Santos: conceptualization, data curation, validation, investigation, visualization, and writing-original draft.

A Moye: investigation.

S-W Park: conceptualization, data curation, formal analysis, supervision, funding acquisition, investigation, and writing-original draft, review, and editing. 


\section{Conflict of Interest Statement}

The authors declare that they have no conflict of interest.

\section{References}

Awad J, Stotz Hum Fekete A, Krischke M, Engert C, Havaux M, Berger S, Mueller MJ (2015) 2-cysteine peroxiredoxins and thylakoid ascorbate peroxidase create a water-water cycle that is essential to protect the photosynthetic apparatus under high light stress conditions. Plant Physiol 167: 1592-1603. doi:10.1104/pp.114.255356

Baier M, Dietz KJ (1999) Protective function of chloroplast 2-cysteine peroxiredoxin in photosynthesis, evidence from transgenic Arabidopsis. Plant Physiol 119: 1407-1414. doi:10.1104/pp.119.4.1407

Baier M, Noctor G, Foyer CH, Dietz KJ (2000) Antisense suppression of 2cysteine peroxiredoxin in Arabidopsis specifically enhances the activities and expression of enzymes associated with ascorbate metabolism but glutathione metabolism. Plant Physiol 124: 823-832. doi:10.1104/pp.124.2.823

Ballaré CL (2014) Light regulation of plant defense. Annu Rev Plant Biol 65: 335-363. doi:10.1146/annurev-arplant-050213-040145

Bosch M, Wright LP, Gershenzon J, Wasternack C, Hause B, Schaller A, Stintzi A (2014) Jasmonic acid and its precursor 12-oxophytodienoic acid control different aspects of constitutive and induced herbivore defenses in tomato. Plant Physiol 166: 396-410. doi:10.1104/ pp. 114.237388

Böttcher C, Pollmann S (2009) Plant osylins: Plant responses to 12-oxophytodienoic acid are governed by its specific structural and functional properties. FEBS J 276: 4693-4704. doi:10.1111/j.17424658.2009.07195.x

Bhuwan M, Suragani M, Entesham NZ, Hasnain SE (2017) Aggregation prevention assay for chaperone activity of proteins using spectroflurometry. Bio Protoc 7: e2107. doi:10.21769/bioprotoc.2107

Calderón A, Lázaro-Payo A, Iglesias-Baena I, Camejo D, Lázaro JJ, Sevilla F, Jiménez A (2017) Glutathionylation of pea chloroplast 2-Cys Prx and mitochondrial Prx IIF affects their structure and reroxidase activity and sulfiredoxin deglutathionylates only the 2-Cys Prx. Front Plant Sci 8: 118. doi:10.3389/fpls.2017.00118

Caporaletti D, D'Alessio AC, Rodriguez-Suarez RJ, Senn AM, Suek PD, Wolosiuk RA (2007) Non-reductive modulation of chloroplast fructose-1,6bisphosphatase by 2-Cys peroxiredoxin. Biochem Biophys Res Commun 355: 722-727. doi:10.1016/j.bbrc.2007.02.013

Cheeseman JM (2006) Hydrogen peroxide concentrations in leaves under natural conditions. J Exp Bot 57: 2435-2444. doi:10.1093/jxb/erl004

Cheong H, Barbosa dos Santos I, Liu W, Gosse HN, Park SW (2017) Cyclophilin 20-3 is positioned as a regulatory hub between light-dependent redox and 12-oxo-phytodienoic acid signaling. Plant Signal Behav 12: e1362520. doi:10.1080/15592324.2017.1362520

Czechowski T, Stitt M, Altmann T, Udvardi MK, Scheible WR (2005) Genomewide identification and testing of superior reference genes for transcript normalization in Arabidopsis. Plant Physiol 139: 5-17. doi:10.1104/pp.105.063743

Dave A, Hernández ML, He Z, Andriotis VME, Vaistij FE, Larson TR, Graham IA (2011) 12-oxo-phytodienoic acid accumulation during seed development re-presses seed germination in Arabidopsis. Plant Cell 23: 583-599. doi:10.1105/tpc.110.081489

Dave A, Graham IA (2012) Oxylipin signaling: A distinct role for the jasmonic acid precursor cis-(+)-12-oxo-phytodienoic acid (cis-OPDA). Front Plant Sci 3: 42. doi:10.3389/fpls.2012.00042
Dietz KJ, Jacob S, Oelze ML, Laxa M, Tognetti V, de Miranda SM, Baier M, Finkemeier I (2006) The function of peroxiredoxins in plant organelle redox metabolism. J Exp Bot 57: 1697-1709. doi:10.1093/jxb/erj160

Dill KA, MacCallum JL (2012) The protein-folding problem, 50 years on. Science 338: 1042-1046. doi:10.1126/science.1219021

Dominguez-Soils JR, He Z, Lima A, Ting J, Buchanan BB, Luan S (2008) A cyclophilin links redox and light signals to cysteine biosynthesis and stress responses in chloroplasts. Proc Natl Acad Sci U S A 105: 16386-16391. doi:10.1073/pnas.0808204105

Finka A, Mattoo RU, Goloubinoff P (2011) Meta-analysis of heat- and chemically upregulated chaperone genes in plant and human cells. Cell Stress Chaperones 16: 15-31. doi:10.1007/s12192-010-0216-8

Glazebrook J, Ausubel FM (1994) Isolation of phytoalexin-deficient mutants of Arabidopsis thaliana and characterization of their interactions with bacterial pathogens. Proc Natl Acad Sci U S A 91: 8955-8959. doi:10.1073/pnas.91.19.8955

Goetz S, Hellwege A, Stenzel I, Kutter C, Hauptmann V, Forner S, McCaig B, Hause G, Mierxch O, Wasternack C, et al (2012) Role of cis-12-oxophytodienoic acid in tomato embryo development. Plant Physiol 158: 1715-1727. doi:10.1104/pp.111.192658

Grek CL, Zhang J, Manevich Y, Townsend DM, Tew KD (2013) Cause and consequences of cysteine S-glutathionylation. J Biol Chem 288: 26497-26504. doi:10.1074/jbc.r113.461368

Guo H-M, Li H-C, Zhou S-R, Xue H-W, Miao X-X (2014) Cis-12-oxo-phytodienoic acid stimulates rice defense response to a piercing-sucking insect. Mol Plant 7: 1683-1692. doi:10.1093/mp/ssu098

Horling F, Lamkemeyer P, König J, Finkemeier I, Kandlbinder A, Baier M, Dietz KJ (2003) Divergent light-, ascorbate-, and oxidative stress-dependent regulation of expression of the peroxiredoxin gene family in Arabidopsis. Plant Physiol 131: 317-325. doi:10.1104/pp.010017

Huot B, Yao J, Montgomery BL, He SY (2014) Growth-defense tradeoffs in plants: A balancing act to optimize fitness. Mol Plant 7: 1267-1287. doi: $10.1093 / \mathrm{mp} / \mathrm{ssu} 049$

Ishiga Y, Ishiga T, Wangdi T, Mysore KS, Uppalapati SR (2012) NTRC and chloroplast-generated reactive oxygen species regulate Pseudomonas syringae pv. tomato disease development in tomato and Arabidopsis. Mol Plant Microbe Interact 25: 294-306. doi:10.1094/ mpmi-05-11-0130

Kangasjärvi S, Lepistö A, Hännikäinen K, Piippo M, Luomala EM, Aro EM, Rintamäki E (2008) Diverse roles for chloroplast stromal and thylakoid-bound ascorbate peroxidases in plant stress responses. Biochem J 412: 275-285. doi:10.1042/bj20080030

Kathurai SV, Chan YH, Nobrega RP, Özen A, Matthews CR (2016) Clusters of isoleucine, leucine, and valine side chains define cores of stability in high-energy states of globular proteins: Sequence determination of structure and stability. Protein Sci 25: 662-675. doi:10.1002/pro.2860

Keszler A, Zhang Y, Hogg N (2009) The reaction between nitric oxide, glutathione and oxygen in the presence and absence of protein: How are S-nitrosothiols formed?. Free Radic Biol Med 48: 55-64. doi:10.1016/j.freeradbiomed.2009.10.026

Kirchsteiger K, Pulido P, González M, Cejudo FJ (2009) NADPH thioredoxin reductase $C$ controls the redox status of chloroplast 2-Cys peroxiredoxins in Arabidopsis thaliana. Mol Plant 2: 298-307. doi: $10.1093 / \mathrm{mp} / \mathrm{ssn} 082$

Koffler BE, Bloem E, Zellnig G, Zechmann B (2013) High resolution imaging of subcellular glutathione concentrations by quantitative immunoelectron microscopy in different leaf areas of Arabidopsis. Micron 45: 119-128. doi:10.1016/j.micron.2012.11.006

Laxa M, Konig J, Dietz KJ, Kandlbidner A (2007) Role of the cysteine residues in Arabidopsis thaliana cyclophilin CYP20-3 in peptidyl-prolyl cis-trans isomerase and redox-related function. Biochem J 401: 287-297. doi:10.1042/bj20061092 
Lee EM, Lee SS, Tripathi BN, Jung HS, Cao GP, Lee Y, Singh S, Hong SH, Lee KW, Lee SY, et al (2015) Site-directed mutagenesis substituting cysteine for serine in 2-Cys peroxiredoxin (2-Cys PrXA) of Arabidopsis thaliana effectively improves its peroxidase and chaperone functions. Ann Bot 116: 713-725. doi:10.1093/aob/mcv094

Liebthal M, Maynard M, Dietz KJ (2019) Peroxiredoxins and redox signaling in plants. Antioxid Redox Signal 28: 609-624. doi:10.1089/ars.2017.7164

Liebthal M, Strüve M, Li X, Hertle Y, Maynard D, Hellweg T, Viehhauser A, Dietz JK (2016) Redox-dependent conformational dynamics of decameric 2cys-teine peroxiredoxin and its interaction with cyclophilin 20-3. Plant Cell Physiol 57: 1415-1425. doi:10.1093/pcp/pcw031

Maruta T, Ogawa T, Tsujimura M, Ikemoto K, Yoshida T, Takahashi H, Yoshimura K, Shigeoka S (2016) Loss-of-function of an Arabidopsis NADPH pyrophosphohydrolase, AtNUDX19, impacts on the pyridine nucleotides status and confers photooxidative stress tolerance. Sci Rep 6: 37432. doi:10.1038/srep37432

Mou Z, Fan W, Dong X (2003) Inducers of plant systemic acquired resistance regulate NPR1 function through redox changes. Cell 113: 935-944. doi:10.1016/s0092-8674(03)00429-x

Motohashi K, Kondoh A, Stumpp MT, Hisabori T (2001) Comprehensive survey of proteins targeted by chloroplast thioredoxin. Proc Natl Acad Sci U S A 98: 11224-11229. doi:10.1073/pnas.191282098

Muench M, Hsin CH, Ferber E, Berger S, Mueller MJ (2016) Reactive electrophilic oxylipins triggers a heat stress-like response through HSFA1 transcription factors. J Exp Bot 67: 6139-6148. doi:10.1093/jxb/ erw376

Muthuramalingam M, Seidel T, Laxa M, Nunes de Miranda SM, Gärtnner F, Ströher E, Kandlbinder A, Dietz KJ (2009) Multiple redox and non-redox interactions define 2-Cys peroxiredoxin as a regulatory hub in the chloroplasts. Mol Plant 2: 1273-1288. doi:10.1093/mp/ssp089

Parisy V, Poinssot B, Owsianowski L, Buchala A, Glazebrook J, Mauch F (2006) Identification of PAD2 as a $y$-glutamylcysteine synthetase highlights the importance of glutathione in disease resistance of Arabiodopsis. Plant J 49: 159-172. doi:10.1111/j.1365-313x.2006.02938.x

Park JW, Mieyal JJ, Rhee SG, Chock PB (2009) Deglutathionylation of 2-Cys peroxiredoxin is specifically catalyzed by sulfiredoxin. J Biol Chem 284: 23364-23374. doi:10.1074/jbc.m109.021394

Park JW, Piszczek G, Rhee SG, Chock PB (2011) Glutathionylation of peroxiredoxin I induces decamer to dimers dissociation with concomitant loss of chaperone activity. Biochemistry 50: 3204-3210. doi:10.1021/bi101373h

Park SW, Li W, Viehhauser A, He B, Kim S, Nilsson AK, Andersson MX, Kittle JD, Ambavaram MM, Luan S, et al (2013) Cyclophilin 20-3 relays a 12-oxophytodienoic acid signal during stress responsive regulation of cellular redox homeostasis. Proc Natl Acad Sci U S A 110: 9559-9564. doi:10.1073/pnas.1218872110

Perkins A, Nelson KJ, Parsonage D, Poole LB, Karplus PA (2015) Peroxiredoxins: Guardians against oxidative stress and modulators of peroxide signaling. Trends Biochem Sci 40: 435-445. doi:10.1016/ j.tibs.2015.05.001

Pulido P, Spinola MC, Kirchsteiger K, Guinea M, Pascual MB, Sahrawy M, Sandalio LM, Dietz KJ, González M, Dejudo FJ (2010) Functional analysis of the pathways for 2-Cys peroxiredoxin reduction in Arabidopsis thaliana chloroplasts. J Exp Bot 61: 4043-4054. doi:10.1093/jxb/erq218

Ramakers C, Ruijter JM, Deprez RHL, Moorman AFM (2003) Assumption-free analysis of quantitative real-time polymerase chain reaction (PCR) data. Neurosci Lett 339: 62-66. doi:10.1016/s0304-3940(02)01423-4

Rose GD, Wolfenden R (1993) Hydrogen bonding, hydrophobicity, packing, and protein folding. Annu Rev Biophys Biomol Struct 22: 381-415. doi:10.1146/annurev.bb.22.060193.002121
Sanchez-Villarreal A, Shin J, Bujdoso N, Obata T, Neumann U, Du SX, Ding Z, Davis AM, Shindo T, Schmelzer E, et al (2013) TIME FOR COFFEE is an essential component in the maintenance of metabolic homeostasis in Arabidopsis thaliana. Plant J 76: 188-200. doi:10.1111/tpj.12292

Scalschi L, Sanmartín M, Camañes G, Troncho P, Sánchez-Serrano JJ, GarcíaAgustín P, Vicedo $B$ (2015) Silencing of OPR3 in tomato reveals the role of OPDA in callose deposition during the activation of defenses against Botrytis cinerea. Plant J 81: 304-315. doi:10.1111/tpj.12728

Sievers F, Wilm A, Dineen D, Gibson TJ, Karplus K, Li W, Lopez R, McWilliam H, Remmert M, Soding J, et al (2011) Fast, scalable generation of highquality protein multiple sequence alignments using Clustal Omega. Mol Syst Biol 7: 539. doi:10.1038/msb.2011.75

Sievers F, Higgins DG (2018) Clustal Omega for making accurate alignments of many protein science. Protein Sci 27: 135-145. doi:10.1002/pro.3290

Stenbaek A, Hansson A, Wulff RP, Hansson M, Dietz KJ, Jensen PE (2008) $\mathrm{NADPH}$-dependent thioredoxin reductase and 2-Cys peroxiredoxins are needed for the protection of Mg-protoporphyrin monomethyl ester cyclase. FEBS Lett 582: 2773-2778. doi:10.1016/ j.febslet.2008.07.006

Stintzi A, Weber H, Reymond P, Browse J, Farmer EE (2001) Plant defense in the absence of jasmonic acid: The role of cyclopentenones. Proc Natl Acad Sci U S A 98: 12837-12842. doi:10.1073/pnas.211311098

Stotz HU, Jikumaru Y, Shimada Y, Sasaki E, Stingl N, Mueller MJ, Kamiya Y (2011) Jasmonate-dependent and COI1-independent defense responses against Sclerotinia sclerotiorum in Arabidopsis thaliana: Auxin is part of Col1-independent defense signaling. Plant Cell Physiol 52: 1941-1956. doi:10.1093/pcp/pcr127

Tada Y, Spoel SH, Paferowska-Mukhtar K, Mou Z, Song J, Wang C, Zuo J, Dong X (2008) Plant immunity requires conformational changes of NPR1 via S-nitrosylation and thioredoxins. Science 321: 952-956. doi:10.1126/ science. 1156970

Takahashi H, Kopriva S, Giordano M, Saito K, Hell R (2011) Sulfur assimilation in photosynthetic organisms: Molecular functions and regulations of transporters and assimilatory enzymes. Annu Rev Plant Biol 62: 157-184. doi:10.1146/annurev-arplant-042110-103921

Udvardi MK, Czechowski T, Scheible WR (2008) Eleven golden rules of quantitative RT-PCR. Plant Cell 20: 1736-1737. doi:10.1105/ tpc.108.061143

Wirtz M, Hell R (2006) Functional analysis of the cysteine synthase protein complex from plants: Structural, biochemical and regulatory properties. J Plant Physiol 163: 273-286. doi:10.1016/j.jplph.2005.11.013

Xiong Y, Uys JD, Tew KD, Townsend DM (2011) S-glutathionylation: From molecular mechanisms to health outcomes. Antioxid Redox Signal 15: 233-270. doi:10.1089/ars.2010.3540

Yoshida K, Hisabori T (2016) Two distinct redox cascades cooperatively regulate chloroplast functions and sustain plant viability. Proc Natl Acad Sci U S A 113: E3967-E3976. doi:10.1073/pnas.1604101113

Zhang Y, Turner JG (2008) Wound-induced endogenous jasmonates stunt plant growth by inhibiting mitosis. PLOS One 3: e3699. doi:10.1371/ journal.pone.0003699

Zhu C, Gao Y, Li H, Meng S, Li L, Francisco JS, Zeng XC (2016) Characterizing hydrophobicity of amino acid side chains in a protein environment via measuring contact angle of a water nanodroplet on planar peptide network. Proc Natl Acad Sci U S A 113: 12946-12951. doi:10.1073/ pnas. 1616138113

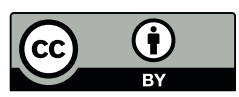

License: This article is available under a Creative Commons License (Attribution 4.0 International, as described at https://creativecommons.org/ licenses/by/4.0/). 